\title{
Therapeutic Effects of Manual Therapy, Transcutaneous Electric Nerve Stimulation, and Forearm Brace on Lateral Epicondylitis: A Randomized Controlled Trial
}

\section{Wolfgang Rachold ( $\square$ wrachold@me.com )}

Practice for General Medicine, University of Rostock

\section{Christoph Berger}

Department for Child and Adolescence Neuropsychiatry, University of Rostock Mail: Gehlsheimer Straße 20, 18147 Rostock, Germany

\section{Olaf Reis}

Department for Child and Adolescence Neuropsychiatry, University of Rostock Mail: Gehlsheimer Straße 20, 18147 Rostock, Germany

\section{Johannes Buchmann}

Department for Child and Adolescence Neuropsychiatry, University of Rostock Mail: Gehlsheimer Straße 20, 18147 Rostock, Germany

\section{Research Article}

Keywords: manual therapy, epicondylalgia, epicondylopathia, epicondylitis, tennis elbow, functional chains, trigger point

Posted Date: February 2nd, 2021

DOl: https://doi.org/10.21203/rs.3.rs-123651/v1

License: (a) This work is licensed under a Creative Commons Attribution 4.0 International License. Read Full License 


\section{Abstract}

Background: Epicondylopathia humeri radialis is often diagnosed by general practitioners. Usually, the therapy comprises transcutaneous electrical nerve stimulation and the application of a forearm brace. Manual therapy is prescribed beyond transcutaneous electrical nerve stimulation and forearm brace, and it is performed by specialized physiotherapists. However, data comparing the effectiveness of all methods are scarce. In this study, the therapeutic effects of manual therapy were compared to those of transcutaneous electrical nerve stimulation and forearm brace along with a combination of all three.

Methods: Fifty-two patients diagnosed with epicondylopathia humeri radialis by a general practitioner were randomized into three treatment arms: 19 patients received a combination of manual therapy, transcutaneous nerve stimulation, and forearm brace; 18 patients received manual therapy only; and 15 patients wore a forearm brace and received transcutaneous nerve stimulation. The primary outcomes included the range of motion and pain intensity. The secondary outcomes were elbow function and psychological well-being. Primary and secondary outcomes were measured before treatment (0), and 4and 8-weeks post-treatment using the Patient Rated Tennis Elbow Evaluation Questionnaire and the Short Form Health Survey Questionnaire.

Results: The range of motion and pain intensity did not differ between the intervention groups.

Conclusions: Manual therapy alone is as effective as combination therapy with transcutaneous nerve stimulation and the use of a forearm brace for epicondylopathia humeri radialis. Hence, there is evidence supporting the inclusion of manual therapy in the guidelines for treating patients with epicondylopathia humeri radialis.

Trial registration: German Clinical Trial Register: DRKS, trial registration number: 00021137, date of registration: 24/03/2020 (retrospectively registered)

\section{Background}

Epicondylopathia humeri radialis (EHR)-also termed lateral epicondylitis or tennis elbow-is a painful disease of the tendon insertions of the lateral elbow. ${ }^{1}$ Guidelines from the American College of Occupational And Environmental Medicine (ACOEM) acknowledge braces and transcutaneous electrical nerve stimulation (TENS) as therapies for EHR, but there have been no recommendations endorsing or opposing these methods. ${ }^{2}$ The ACOEM guidelines do not recommend mobilization. In Germany, EHR is commonly treated by physiotherapists with manual therapy (MT), as prescribed by physicians, even though the exclusive treatment of EHR with MT is not recommended in the current guidelines. ${ }^{1}$ Furthermore, German guidelines recommend "epicondylitis-bandages," although there is little evidence supporting this method of treatment. ${ }^{3}$ TENS was used in combination with a forearm brace (FB), as this is widely used for treating EHR in Germany. 
A literature review was conducted in PubMed using broad MeSH-terms, such as manual therapy (MT), epicondylalgia, epicondylopathia, and epicondylitis (Table 1). MT included the terms manual therapy, manual medicine, physiotherapy, thrust technique, myofascial technique, manipulation, and muscle energy techniques.

Table 1

Studies of manual therapy for the treatment of EHR

\begin{tabular}{|lll|}
\hline Author & Year & Result \\
\hline Rompe $^{4}$ & 2001 & $\begin{array}{l}\text { MT has no additional benefit compared to TENS at the cervicothoracic } \\
\text { junction }\end{array}$ \\
\hline $\begin{array}{l}\text { Nourbakhsh }{ }^{5} \\
2008\end{array}$ & $\begin{array}{l}\text { Cranio-sacral therapy is superior to placebo (RCT) } \\
\begin{array}{l}\text { Coombes BK, } \\
\text { Bisset L, } \\
\text { Vicenzino B. }\end{array}\end{array} 2014$ & $\begin{array}{l}\text { Cervical dysfunction is found in individuals with lateral epicondylitis who } \\
\text { do not have obvious neck pain. This dysfunction suggests central } \\
\text { sensitization mechanisms (cross-sectional case-control study) }\end{array}$ \\
$\begin{array}{l}\text { Lucado AM, } \\
\text { Dale RB, } \\
\text { Vincent J, Day } \\
\text { JM. }\end{array}$ & 2019 & $\begin{array}{l}\text { Joint mobilization improves pain and functional grip scores compared to } \\
\text { control groups (systematic review and meta-analysis) }\end{array}$ \\
\hline $\begin{array}{l}\text { MT includes the terms manual therapy, physiotherapy, thrust technique, myofascial technique, } \\
\text { manipulation, and muscle energy technique. } \\
\text { EHR: epicondylopathia humeri radialis; RCT: randomized controlled trial. }\end{array}$ \\
\hline
\end{tabular}

Unyo et al. reported increased muscle imbalances and fatigability in patients with EHR compared to those in healthy controls. ${ }^{8}$ Therefore, the relaxation of muscles using $\mathrm{MT}^{9}$ is indicated. Dommerholt et al. ${ }^{10}$ described myofascial pain as a prevalent type of musculoskeletal pain accepted by the International Association of Pain. The presence of trigger points (TRP) can be confirmed by magnetic resonance imaging (MRI) and sonography studies. Manual TRP-release is a special type of MT that appears to increase the pain threshold. However, MT of the cervical spine and cervicothoracic junction has been reported as ineffective for the treatment of EHR. ${ }^{4}$ In a randomized, double-blind study, ${ }^{5}$ craniosacral therapy, a special type of MT, was found to be effective in treating EHR. Thus, the results of these studies indicate that MT is a very effective treatment for EHR.

A second literature search of PubMed included the keywords epicondylopathia, epicondylalgia, epicondylitis, TENS, epicondylopathia, epicondylalgia, epicondylitis, and forearm brace (Table 2). One study reported that low-frequency electricity is an effective treatment for EHR. ${ }^{13}$ Bandages have been reported to have minimal effects, except for braces influencing the extensor muscles. ${ }^{11}$ Therefore, forearm extensor braces were used in this study. 
Herein, the therapeutic effect of MT performed by specialized physiotherapists compared to the combination of FB and TENS was examined. Although pain medications (including nonsteroidal antiinflammatory drugs [NSAIDs]) are recommended in the German guidelines, they were not included in this study.

Table 2

TENS and forearm brace for the treatment of EHR

\begin{tabular}{|lcl|}
\hline Author & Year & Results \\
\hline $\begin{array}{l}\text { Struijs PA, Smidt N, Arola H, Dijk } \\
\text { v C, Buchbinder R, Assendelft WJ } \\
3\end{array}$ & 2002 & $\begin{array}{l}\text { No definitive conclusions can be drawn concerning the } \\
\text { effectiveness of orthotic devices for lateral epicondylitis }\end{array}$ \\
\hline Faes M ${ }^{11}$ & 2006 & FB effective compared to no FB (level 1 RCT) \\
\hline $\begin{array}{l}\text { Struijs PA, Korthals-de Bos IB, } \\
\text { van Tulder MW, van Dijk CN, } \\
\text { Bouter LM, Assendelft WJ }{ }^{12}\end{array}$ & 2006 & $\begin{array}{l}\text { No clinically relevant or statistically significant } \\
\text { differences in costs were identified between } \\
\text { physiotherapy, braces, and the combination of both } \\
\text { treatments }\end{array}$ \\
\hline Rodriguez ${ }^{13}$ & 2011 & $\begin{array}{l}\text { TENS is effective for the treatment of TRP with a } \\
\text { decrease in sensitivity for pressure pain and an increase } \\
\text { in mobility of the cervical spine (RCT) }\end{array}$ \\
\hline $\begin{array}{l}\text { TENS: transcutaneous electrical nerve stimulation; EHR: epicondylopathia humeri radialis; FB: } \\
\text { forearm brace; TRP: trigger points; RCT: randomized controlled trial }\end{array}$ \\
\hline
\end{tabular}

\section{Methods}

\section{Study Design}

There were three treatment arms: MT, a combination of TENS and FB, and a combination of MT, TENS, and FB. The add-on effect of MT was evaluated by comparing TENS and FB to TENS, FB, and MT.

The primary and secondary outcomes were measured at baseline, and both at 4 and 8 weeks posttreatment.

The primary outcomes included range of motion (ROM) and the intensity of pain measured using the visual analog scale (VAS) (pain range: 1-10). The VAS is a valid and widely applied tool that is used for assessing musculoskeletal pain. ${ }^{14}$ ROM was measured using flexion and extension of the elbow in geometrical degrees using a goniometer. ${ }^{15}$

The secondary outcomes included elbow function and psychological well-being, measured using the Patient Rated Tennis Elbow Evaluation Questionnaire (PRTEE) and the Short Form Health Survey Questionnaire (SF-36), respectively. The PRTEE characterizes the elbow function and pain using ten items related to joint malfunction and five items related to pain. ${ }^{16}$ Each item is scored (range: $0-10$ ), and the 
sum of the scores is used as the total PRTEE score. For this study, the PRTEE items were translated into German and read aloud to the patients. SF-36 is widely used for the measurement of health-related quality of life (HRQOL) and contains eight domains: vitality, functional capability, pain, perception of health, physical, emotional, and social functioning, and physical well-being. ${ }^{17}$ Scores for each domain range between 0 and 100, with 100 indicating full satisfaction; the total sum of the scores is used. The total scores and the subscores for pain and vitality were evaluated, and a version of the SF-36 that has been standardized for use in Germany was used in this study. ${ }^{18}$

Before starting with the enrollment, the study was approved by the ethics committee (University of Rostock, Germany, number of registration: A2012-0146, at 19/12/2012) and retrospectively registered as a clinical trial (German Clinical Trial Register: DRKS, trial registration number: 00021137, date of registration 24/03/2020).

\section{Patients}

Patients diagnosed with EHR were randomized into one of three treatment arms. Patients were randomized with allocation concealment using Randomizer $\rightarrow$ software by MEDSHARING, 44 Rue Roger Salengro, 94120 Fontenay Sous Bois, France, http://www.ercf-medsharing.com/(cited 27.10.2020). The physician (corresponding author) evaluating the patient outcomes was blinded to the patient groups.

Patients who fulfilled the following inclusion criteria were consecutively enrolled in the study: between 18 and 65 years old, diagnosed with EHR (as described below), and provided informed consent. EHR was diagnosed if the reported pain was in the lateral region of the elbow and was provoked by extension of the hand (positive provocation test). Other diseases or injuries were excluded prior to the diagnosis, with structural causes excluded using X-ray imaging.

The exclusion criteria were as follows: injuries to the arm or cervical spine during 6 months prior to presentation, acute or chronic infection, rheumatic diseases, osteochondrosis dissecans, advanced osteoarthritis of the elbow, pregnancy, diabetes, malignancy, malformation in the upper extremities, circulatory disorder in the upper extremities, radicular syndrome at C6, chronic pain syndrome, psychiatric disorders, neuropathy, myopathy, the use of beta-blockers, statins, or NSAIDS, or incomplete data.

Of the 52 patients included in this study, 18 received MT, 15 received a combination of TENS and FB, and 19 received a combination of MT, TENS, and FB (Table 3). Patient recruitment was discontinued after attaining the required number of participants specified in the statistical analysis section. 
Table 3

Patients' age and sex

\begin{tabular}{|lllll|}
\hline & MT & TENS + FB & MT + TENS + FB & P-value \\
& $(\mathbf{n = 1 8 )}$ & $(\mathbf{n = 1 5 )}$ & $(\mathbf{n = 1 9 )}$ & \\
\hline Age, years & $48.06 \pm 9.65$ & $45.67 \pm 9.686$ & $45.89 \pm 9.37$ & 0.72 \\
\hline Sex (female:male) & $12: 6$ & $10: 5$ & $9: 10$ & 0.394 \\
\hline Continuous variables are presented as mean \pm standard deviation. & \\
FB: forearm brace; MT: manual therapy; TENS: transcutaneous electrical nerve stimulation \\
\hline
\end{tabular}

Treatment

MT consisted of manipulation of the joints, muscles, or fascia by a specialized therapist who received correspondence from the primary physician regarding functional chains and TRP. Functional chains, including the elbow joint, often contain TRP of the shoulder girdle and are associated with segmental dysfunctions of the cervical spine. When therapists observed functional chains, they were included in the treatment. Electrotherapy was comprised biphasic TENS-mode at $300 \mathrm{~ms}$ and $50 \mathrm{~Hz}$ for analgesia and detonization, respectively. MT and TENS treatments were performed for $~ 20$ minutes, twice per week, and over a 3-week period. An extensor FB was used to provide constant mechanical therapy in the appropriate study groups.

\section{Statistical Analysis}

Statistical significance was set at $P<0.05$. The number of patients required for repeated measures of variance (ANOVA) for three groups and three points of measurement on within-between-group effects assuming an alpha-error level of $5 \%$, a level for the beta error of $20 \%$, an assumed effect size of 0.25 , and a power to detect between-group differences of $80 \%$ was calculated. ANOVA is a statistical method that calculates variances and test variables in order to obtain information on the laws behind the data to determine the differences between groups. The Statistical Package for Social Sciences software (IBM $\rightarrow$ ) was used for statistical calculations. The correlation between repeated measures was assumed to be 0.5 , with the lowest boundary possible for non-sphericity corrections set at 0.5 . The number of participants required for the total sample was $52 .{ }^{19}$ One ANOVA per dependent variable was conducted.

\section{Results}

The demographic data for all patients are shown in Table 3. There were no significant differences between the treatment groups in terms of age or gender.

The PRTEE score $(p=0.004)$ and ROM $(p=0.001)$ significantly improved from baseline to 8 weeks posttreatment. However, there were no differences in PRTEE scores or ROM between the treatment groups. Although there was a decrease in the VAS score over time, the change was not significant. Subjective 
HRQOL measured by the total SF-36 score did not change significantly over time and was not significantly different between the groups (Table 4). Also, the sub-scores for pain and vitality were not significantly different between the groups (data not shown). An additional file shows this in more detail [see Additional file 1].

Table 4

Changes in elbow function, range of motion, and pain and psychological well-being

\begin{tabular}{|c|c|c|c|c|}
\hline & & $\begin{array}{l}\text { MT } \\
n=18\end{array}$ & $\begin{array}{l}\text { TENS }+ \text { FB } \\
(n=15)\end{array}$ & $\begin{array}{l}\text { MT + TENS + FB } \\
\mathrm{n}=19\end{array}$ \\
\hline \multirow[t]{4}{*}{ PRTEE } & Baseline & $41.03 \pm 17.52$ & $39.7 \pm 16.29$ & $42.29 \pm 15.16$ \\
\hline & 4 weeks & $34.83 \pm 12.62$ & $30.67 \pm 18.71$ & $33.16 \pm 14.8$ \\
\hline & post-treatment & & & \\
\hline & 8 weeks post-treatment & $22.81 \pm 12.78$ & $20.33 \pm 17.17$ & $28.03 \pm 16.15$ \\
\hline \multirow[t]{3}{*}{ ROM } & Baseline & $140.78 \pm 9.21$ & $140.93 \pm 8.93$ & $141.37 \pm 4.9$ \\
\hline & 4 weeks post-treatment & $143.22 \pm 6.93$ & $145.47 \pm 7.42$ & $144.95 \pm 6.81$ \\
\hline & 8 weeks post-treatment & $144.94 \pm 7.76$ & $145 \pm 9.16$ & $148.26 \pm 6.72$ \\
\hline \multirow[t]{3}{*}{ VAS } & Baseline & $5.22 \pm 1.83$ & $5.87 \pm 1.54$ & $5.45 \pm 1.09$ \\
\hline & 4 weeks post-treatment & $4.06 \pm 1.42$ & $4.23 \pm 2.33$ & $4.32 \pm 1.89$ \\
\hline & 8 weeks post-treatment & $2.61 \pm 1.42$ & $2.73 \pm 1.85$ & $3.24 \pm 1.88$ \\
\hline \multirow[t]{3}{*}{ SF-36 } & Baseline & $61.64 \pm 17.8$ & $70.7 \pm 12.41$ & $65.13 \pm 15.14$ \\
\hline & 4 weeks post-treatment & $64.35 \pm 17.8$ & $73.04 \pm 14.73$ & $66.66 \pm 15.71$ \\
\hline & 8 weeks post-treatment & $73.31 \pm 14.16$ & $81.82 \pm 14.52$ & $71.79 \pm 14.4$ \\
\hline \multicolumn{5}{|c|}{ Variables are shown as mean \pm standard deviation. } \\
\hline \multicolumn{5}{|c|}{$\begin{array}{l}\text { FB: forearm brace; MT: manual therapy; PRTEE: Patient Rated Tennis Elbow Evaluation Questionnaire } \\
\text { ROM: range of motion (flexion, degrees); SF-36: Short Form Health Survey Questionnaire; TENS: } \\
\text { transcutaneous electrical nerve stimulation; VAS: visual analog scale. }\end{array}$} \\
\hline
\end{tabular}

\section{Discussion}

Significant improvements were observed within 2 months in all treatment arms. Elbow function and ROM improved independent of the treatment, indicating that MT is as effective as TENS and FB for EHR. However, the results of this study also reveal that MT had no additional effect when combined with TENS and $\mathrm{FB}$. 
According to Mohr et al., ${ }^{20}$ the pain of EHR is not exclusively caused by structure-associated lesions, such as the bulging of extensor-sinews, edema, or other MRI findings. The presence of these lesions on MRI also does not correlate with subjective pain ratings. ${ }^{21}$ Manual therapy addresses not only the elbow bones but the functional chains in the musculoskeletal system that are associated with her as well. The functional chains may represent segmental dysfunctions in the cervical spine or TRP in the shoulder or the extensor muscles of the forearm. Physiotherapists were prompted to diagnose and treat functional chains and TRP, which may affect the therapeutic effect of MT observed in this study. The target structures for MT include joints (especially in the elbow and cervical spine), muscles (TRP within the shoulder belt), and the fascia of the upper extremity.

Cloward et al. ${ }^{22}$ described referred pain after irritation of the intervertebral discs of the cervical spine that resembled EHR, as it radiated into the arm and shoulder (the Cloward -zones) after irritation of the intervertebral discs between $\mathrm{C} 4$ and $\mathrm{C} 6$. The intensity of the structures on T1-weighted MRIs has been reported not to be correlated with the patient's subjective pain. ${ }^{21}$ These results support the hypothesis of the nociceptive supply of the intervertebral discs in the cervical spine, which may account for the pain radiating to the elbow. Yamashita et al. ${ }^{23}$ reported mechanosensitive afferent nerves of lumbar facet joints and the surrounding tissue in rabbits that included proprioceptors with low thresholds and high line velocity and nociceptors with high thresholds and low line velocity. MT on joints may alter proprioceptive inputs at the spinal cord, which may contribute to its therapeutic effect in patients with EHR.

TRP provide another promising mechanism for the treatment with MT. According to Simons et al., ${ }^{24}$ TRP are defined as areas within the muscle that can produce referred pain. TRP differ from non-tensed muscles, as they have reduced distances to the endomysium, fragmented or worn-out muscle fibers, atrophy of type II fibers, and necrosis. ${ }^{25}$ TRP have been reported to have a higher $\mathrm{pH}$ and higher concentrations of bradykinin, substance $\mathrm{P}$ (SP), calcitonin gene-related peptide (CGRP), tumor necrosis factor-alpha, interleukins $1 \mathrm{~b}, 6$, and 8 , norepinephrine, and other inflammatory mediators. Active TRP possessed the highest concentrations of these mediators, ${ }^{26}$ and taut-bands (tensed regions of muscle tissue) have been identified on magnetic resonance elastography. ${ }^{25}$ The manipulation of TRP during MT may alter nociception in these regions, which may contribute to its therapeutic effect.

Buchmann et al. ${ }^{27}$ measured the changes in tension within TRP before and during neuromuscular blockage (general anesthesia) and found that segmental interneuronal changes may play a role in the pathophysiology of TRP. Fernandez-Carnero et al. ${ }^{28}$ described both central and peripheral mechanisms of sensitization of TRP in the forearm for patients with EHR compared to those of healthy controls.

There are no studies specifically focusing on pain development in the elbow, as it relates to the fascia. Tesarz et al. ${ }^{29}$ reported that the thoracolumbar fascia (TLF) is important for deep back pain in a rat model, as the concentrations of SP and CGRP in the outer fascia and subcutis were elevated. The hyperexcitability of spinal neurons and deep structures of the back (muscles and TLF) generated new receptor fields after a second injection of nerve growth factor suggesting that the development of back 
pain is a complex interaction that involves the fascia. ${ }^{30}$ This type of interaction may also be present in EHR pain, and MT may alter the afferent input from these target tissues on a segmental neuronal level.

Generally, the results of previous studies do not support the theory of a single, local cause of EHR pain. On the contrary, the results indicate that spinal neuronal mechanisms of sensitization also contribute to EHR pain, suggesting that MT on target tissues may affect the segmental neuronal level of arousal and, therefore, contribute to the nociceptive turnover in the perception of pain.

The present study has some limitations. First, the PRTEE has not been validated for use in Germany and was translated for the purpose of this study. Due to its high reliability and international approval, the usefulness of the PRTEE was assumed in the study and was, therefore, administered to the participants. Second, MT was provided by different therapists, and no data is available regarding the experience of or specific methods used by the therapists. Third, although forearm braces are commonly used in Germany, there is no evidence from randomized controlled trials supporting their use. Finally, this study did not evaluate the use of concomitant medications, such as analgesics. Future research to further evaluate this subject area is necessary.

\section{Conclusion}

Patients with EHR are likely to suffer from functional chains in the musculoskeletal system, which can be effectively treated with MT. MT alone is as effective as combination therapy with TENS and FB for EHR. Hence, there is evidence to support the inclusion of MT in the guidelines for treating patients with EHR.

\section{List Of Abbreviations}

ACOEM- American College of Occupational and Environmental Medicine

CGRP- Calcitonin gene-related peptide

EHR- Epicondylopathia humeri radialis

FB- Forearm brace

HRQOL- Health-related quality of life

MRI- Magnetic resonance imaging

MT- Manual therapy

NSAIDs- Nonsteroidal anti-inflammatory drugs

PRTEE- Patient Rated Tennis Elbow Evaluation Questionnaire

ROM- Range of motion 
SF-36- Short Form Health Survey Questionnaire

SP- Substance P

TENS- Transcutaneous electrical nerve stimulation

TLF- Thoracolumbar fascia

TRP- Trigger points

VAS- Visual analog scale

\section{Declarations}

\section{Ethics approval and consent to participate:}

The study was approved by the ethics committee (University of Rostock, Germany, number of registration: A2012-0146, at 19/12/2012). Informed consent to participate in the study was obtained from the participants. We confirm that all methods were performed in accordance with the relevant guidelines and regulations of the ethics committee.

\section{Consent for publication:}

Not applicable. The requirement for informed consent for publication was waived as no patientidentifying information was included in this study.

\section{Availability of data and materials:}

All data generated and analyzed during this study are included in this published article (and its supplementary files). The datasets used and/or analysed during the current study are available from the corresponding author on reasonable request.

\section{Competing interests:}

The authors declare that they have no competing interests.

\section{Funding:}

The study received no support, including funding, grants, or equipment. By publishing this study, the authors did not receive financial benefit. 


\section{Authors' contributions:}

Reis, Olaf PhD: interpretation of data; Berger, Christoph PhD: analysis of data; Buchmann, Johannes PhD: design of the work, substantively revised the study; Rachold, Wolfgang MD (first author): design of the work, acquisition of data (location as described in "affiliations") writing the manuscript. All authors read und approved the final manuscript.

\section{Acknowledgments:}

We would like to thank Editage (www.editage.com) for English language editing.

\section{References}

1. Tischer T. S2k - Leitlinie Epicondylopathia radialis humeri (German guidelines epicondylopathia humeri radialis) 2019. https://www.awmf.org/leitlinien/detail/Il/033-019.html. Accessed 24 June 2019.

2. Hegmann KT, Hoffman HE, Belcourt RM, Byrne K, Glass L, Melhorn MJ, et al. ACOEM Practice guidelines: elbow disorders. J Occup Environ Med. 2013;55:1365-74.

3. Struijs PA, Smidt N, Arola H, van Dijk CN, Buchbinder R, Assendelft WJJ. Orthotic devices for the treatment of tennis elbow. Cochrane Database Syst Rev. 2002;CD001821.

4. Rompe JD, Riedel C, Betz U, Fink C. Chronic lateral epicondylitis of the elbow: A prospective study of low-energy shockwave therapy and low-energy shockwave therapy plus manual therapy of the cervical spine. Arch Phys Med Rehabil. 2001;82:578-82.

5. Nourbakhsh MR, Fearon FJ. The effect of oscillating-energy manual therapy on lateral epicondylitis: a randomized, placebo-control, double-blinded study. J Hand Ther. 2008;21:4-13.

6. Coombes BK, Bisset L, Brooks P, Khan A, Vicenzino B. Effect of corticosteroid injection, physiotherapy, or both on clinical outcomes in patients with unilateral lateral epicondylalgia: a randomized controlled trial. JAMA. 2013;309:461-9.

7. Lucado AM, Dale RB, Vincent J, Day JM. Do joint mobilizations assist in the recovery of lateral elbow tendinopathy? A systematic review and meta-analysis. J Hand Ther. 2019;32:262-76.

8. Unyo C, Chaler J, Rojas-Martinez M, Pujol E, Müller MB, Garreta R, et al. A cross-sectional study comparing strength profile of dorsal and palmar flexor muscles of the wrist in epicondylitis and healthy men. Eur J Phys Rehabil Med. 2013;49:507-15.

9. Chaitow L. Muscle Energy Techniques. 3rd ed. London: Churchill Livingstone; 2006.

10. Dommerholt J. How have the views on myofascial pain and its treatment evolved in the past 20 years? From spray and stretch and injections to pain science, dry needling and fascial treatments. Pain Manag. 2020;10:63-6. 
11. Faes M, van den Akker B, de Lint JA, Kooloos JG, Hopman MT. Dynamic extensor brace for lateral epicondylitis. Clin Orthop Relat Res. 2006;442:149-57.

12. Struijs PAA, Korthals-de Bos IBC, van Tulder MW, van Dijk CN, Bouter LM, Assendelft WJJ. Cost effectiveness of brace, physiotherapy, or both for treatment of tennis elbow. Br J Sports Med. 2006;40:637-43.

13. Rodriguez-Fernandez AL, Garrido-Santofimia V, Gueita-Rodriguez J, Fernandez-de-Las-Penas C. Effects of burst-type transcutaneous electrical nerve stimulation on cervical range of motion and latent myofascial trigger point pain sensitivity. Arch Phys Med Rehabil. 2011;92:1353-8.

14. Fahndrich E, Linden M. Reliability and validity of the Visual Analogue Scale (VAS) (author's transl). Pharmacopsychiatria. 1982;15:90-4.

15. van de Pol RJ, van Trijffel E, Lucas C. Inter-rater reliability for measurement of passive physiological range of motion of upper extremity joints is better if instruments are used: a systematic review. $J$ Physiother. 2010;56:7-17.

16. Rompe JD, Overend TJ, MacDermid JC. Validation of the Patient-rated Tennis Elbow Evaluation Questionnaire. J Hand Ther. 2007;20:3-10.

17. Tarlov AR, Ware JE Jr, Greenfield S, Nelson EC, Perrin E, Zubkoff M. The Medical Outcomes Study. An application of methods for monitoring the results of medical care. JAMA. 1989;262:925-30.

18. Bellach B, Ellert U. The application of the Short Form Questionnaire 36 within the National Health Survey - first results and new questions. Bundesgesundheitsblatt- GesundheitsforschungGesundheitsschutz. 2000;43:210-6.

19. Erdfelder E, Faul F,Buchner A. GPOWER: a general power analysis program. Behav Res Methods Instrum Comput. 1996;28:1-11.

20. Mohr W. Insertionstendinopathie. Pathologie des Bandapparates (Pathology of the Tendons and Ligaments). Springer; 1987. p. 59-275 (book in German)

21. Savnik A, Jensen B, Norregaard J, Egund N, Danneskiold-Samsoe B, Bliddal H. Magnetic resonance imaging in the evaluation of treatment response of lateral epicondylitis of the elbow. Eur Radiol. 2004;14:964-9.

22. Cloward RB. Cervical diskography. A contribution to the etiology and mechanism of neck, shoulder and arm pain. Ann Surg. 1959;150:1052-64.

23. Yamashita T, Cavanaugh JM, el-Bohy AA, Getchell TV, King Al. Mechanosensitive afferent units in the lumbar facet joint. J Bone Joint Surg Am. 1990;72:865-70.

24. Simons DG. New views of myofascial trigger points: etiology and diagnosis. Arch Phys Med Rehabil. 2008;89:157-9.

25. Windisch A, Reitinger A, Traxler H, Radner H, Neumayer C, Feigl W, et al. Morphology and histochemistry of myogelosis. Clin Anat. 1999;12:266-71.

26. Shah JP, Danoff JV, Desai MJ, Parikh S, Nakamura LY, Philips TM, et al. Biochemicals associated with pain and inflammation are elevated in sites near to and remote from active myofascial trigger 
points. Arch Phys Med Rehabil. 2008;89:16-23.

27. Buchmann J, Neustadt B, Buchmann-Barthel K, Rudolf S, Klauer T, Reis O, et al. Objective measurement of tissue tension in myofascial trigger point areas before and during the administration of anesthesia with complete blocking of neuromuscular transmission. Clin J Pain. 2014;30:191-8.

28. Fernandez-Carnero J, Fernandez-de-Las-Penas C, de la Llave-Rincon Al, Ge HY, Arendt-Nielsen L. Prevalence of and referred pain from myofascial trigger points in the forearm muscles in patients with lateral epicondylalgia. Clin J Pain. 2007;23:353-60.

29. Tesarz J, Hoheisel U, Wiedenhofer B, Mense S. Sensory innervation of the thoracolumbar fascia in rats and humans. Neuroscience. 2011;194:302-8.

30. Hoheisel U, Reuter R, de Freitas MF, Treede RD, Mense S. Injection of nerve growth factor into a low back muscle induces long-lasting latent hypersensitivity in rat dorsal horn neurons. Pain. 2013;154:1953-60.

\section{Figures}




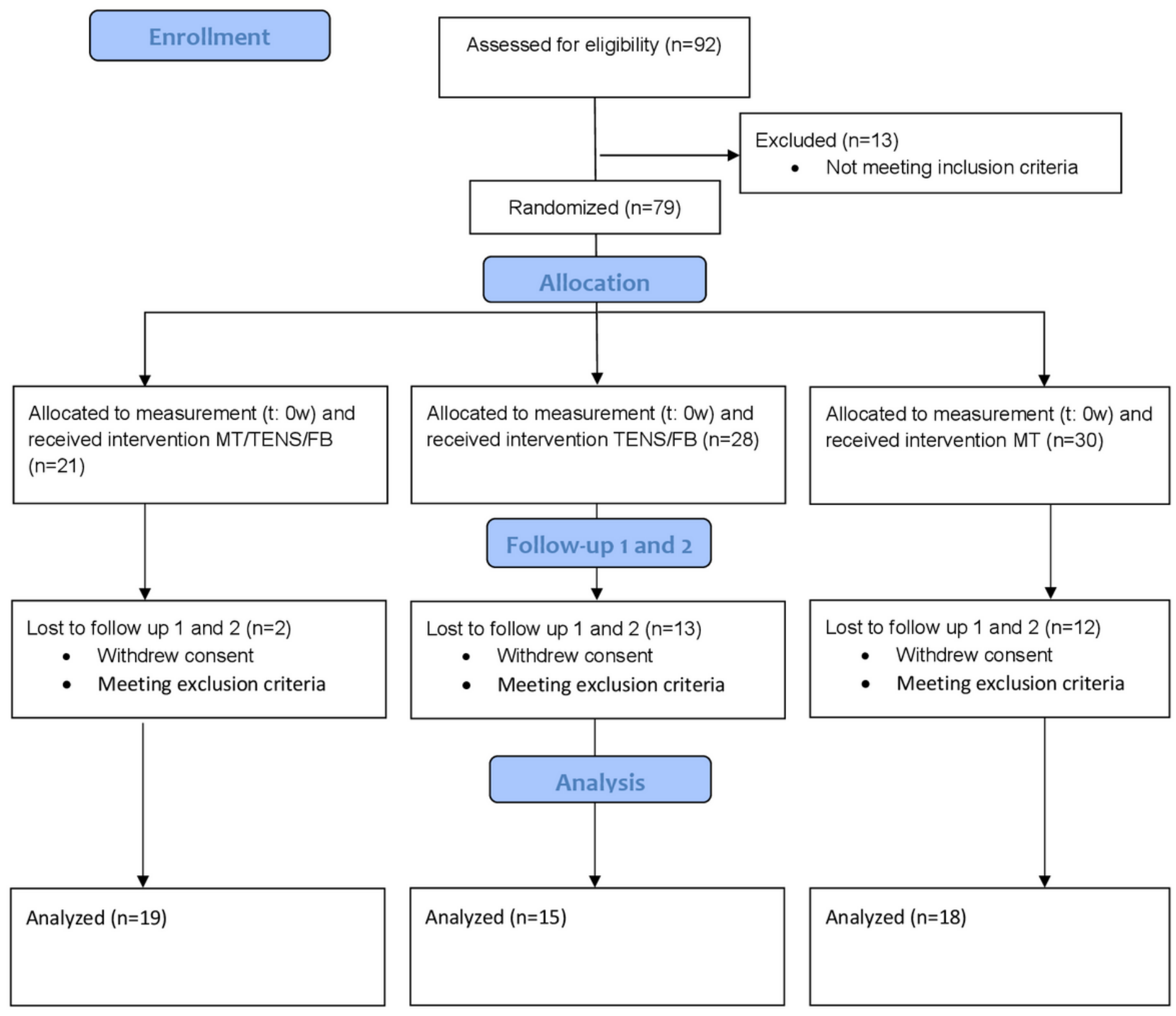

\section{Figure 1}

Consort 2010 Flow Diagram FB: forearm brace; MT: manual therapy; TENS: transcutaneous electrical nerve stimulation. Follow-up 1: Measurement of primary and secondary outcomes 4 weeks post treatment. Follow-up 2: Measurement of primary and secondary outcomes 8 weeks post treatment. Figure 1 describes every work process of the study (blue boxes; e.g. enrollment, allocation...) with the corresponding number of patients (white boxes), as far as it was comprehensible from the study documents.

\section{Supplementary Files}

This is a list of supplementary files associated with this preprint. Click to download. 
- Additionalfile1.xlsx

Page 15/15 